\title{
PERANCANGAN APLIKASI ABSENSI SMP TERANG BAGI BANGSA
}

\section{BUILDING ATTENDANCE APPLICATION FOR TERANG BAGI BANGSA JUNIOR HIGH SCHOOL}

\author{
Ari Yunus Hendrawan', Bagus Aprilio², Ruth Aprilia Wesley ${ }^{3}$ \\ ${ }^{1}$ STMIK AKI PATI \\ ${ }^{2}$ STMIK AKI PATI \\ ${ }^{3}$ UNIVERSITAS AKI \\ 19aritubil@gmail.com, ${ }^{2}$ bagusaprilo@gmail.com, ${ }^{3}$ ruth.wesley27@gmail.com
}

\begin{abstract}
Abstrak
Daftar Kehadiran dapat dilakukan secara online dengan menggunakan aplikasi dengan perancangan database dan desain antar muka pada sistem android mobile. Aplikasi ini membantu admin dan guru dalam mengelolah data dan mempermudah guru dalam melakukan absensi di sekolah. Ketepatan waktu dan kehadiran guru juga dapat dikontrol oleh aplikasi ini. Data yang diolah oleh aplikasi ini adalah data nama tenaga pengajar dan nomor induk pegawai. Menu utama aplikasi ini hanya memiliki beberapa button, sehingga pengguna tidak akan bingung dengan button-buttonnya. use case diagram menunjukkan halaman admin yang memiliki fungsi mengawasi dan fungsi pengaturan untuk menjalankan aplikasi absensi tenaga pengajar dan pengguna android dalam hal ini ialah guru SMP Terang Bagi Bangsa. Model Class Diagram menggambarkan struktur sistem dari pendefinisian kelas yang akan dibuat untuk membangun sistem. Class diagram ini memberikan detail alur dari aplikasi yang akan dibuat. Flowchart menunjukkan alur atau prosedur sistem secara logika. Perancangan antar muka (interface) menampilkan beberapa menu seperti home, menu absensi kelas, input absensi, dan hasil absensi.
\end{abstract}

Kata kunci : aplikasi absensi, perancangam database, perancangan antarmuka,

\begin{abstract}
Online attendance application can be created by database and interface design baseball on Android mobile system. This application helps admin and teachers to manage data and school attendance. Teacher's punctuality and attendance also can be controlled by this application. The Data that be processed by this application are the teacher names and their employe numbers. Main menu of this application have only few buttons, so the users won't get confused with this simple interface. (use case diagram) shows the admin page that has controlling function and setting function in order to run this teacher attendance application of Terang Bagi Bangsa Junior High School. The Diagram Class Model describes the system structure of defining classes that will be created to build the system. This diagram class provides the flow detail of application that will be created. Flowchart shows the flow or procedure of system logically. The design of interface shows several menus such as home, class attendance, attendance input, and attendance result.
\end{abstract}

Keywords: building attendance application, database designer, interface designer

\section{PENDAHULUAN}

Semakin berkembangnya teknologi informasi saat ini, sangat membantu dan mempermudah penggunaan disegala bidang. Kini kebutuhan informasi menjadi hal yang sangat dibutuhkan oleh 
semua orang. Terlebih, kebutuhan informasi yang akurat, cepat, dan tepat untuk digunakan dalam dasar pengambilan keputusan.

Dalam dunia pendidikan, peran perkembangan teknologi informasi sangat penting. Teknologi informasi merupakan suatu hal yang sering dimanfaatkan untuk meningkatkan kualitas dalam lembaga pendidikan, dari proses kegiatan pembelajaran sampai dengan pengelolaan manajemen informasi sekolah dalam upaya mendukung pendidikan.

Di karenakan di SMP Terang Bagi Bangsa memiliki masalah pada absensi siswa dikarenakan wabah corona ini yang masih belum selesai diberantas dan masih membuat siswa maupun masyarakat sekitar sulit mengatur ekonomi karena itu peneliti membuat aplikasi presensi yang dimana untuk membantu siswa smp terang bagi bangsa agar bisa lebih efisien dalam menjalankan absensi.

Melihat dari situasi dan kondisi di atas, maka peneliti akan membahas konsep "PERANCANGAN APLIKASI ABSENSI SMP TERANG BAGI BANGSA BERBASIS ANDROID”. Rancangan ini dimaksudkan untuk memberikan kemudahan kepada SMP Terang Bagi Bangsa.

\section{DASAR TEORI DAN METODOLOGI}

Menurut (Hanifudin ,2010), menyatakan bahwa android merupakan sistem operasi untuk telepon seluler yang berbasis Linux. Android menyediakan platform open source untuk para pengembang guna menjadikan aplikasi yang dipergunakan bagi bermacam perangkat bergerak. Berawal dari Google Inc. membeli Android Inc. Pendatang baru membuat perangkat lunak untuk ponsel. Setelah mengembangkan Android maka diciptakanlah Open Handset Alliance yaitu konsorsium dari 34 perusahaan perangkat keras, perangkat lunak dan telekomunikasi mencakup Google, HTC, Intel, Motorola, Qualcomm, T-mobile dan Nvidia.

APP Inventor ,merupakan suatu aplikasi builder untuk menjadikan aplikasi yang dijalankan pada sistem oprasi android yang diberikan oleh google labs guna menciptakan aplikasi android yang bermodalkan koneksi internet dan browser (Arifudin, 2015).

Perencanaan yang dibuat akan dicadangkan secara online sehingga membantu dalam penyelesaian perencananan ini secara bertingkat. Sekalipun aplikasi inventor ini terbatas tetapi masih banyak aplikasi yang mendukung, misalkan game dengan Grafis 2D dan animasi, utility, Aplikasi Multimedia, GPS, Navigasi dan masih banyak lagi.

Aplikasi inventor mengijinkan pemakai baru dalam memprogram komputer guna membuat aplikasi perangkat lunak untuk sistem android. Aplikasi inventor memakai sistem grafis antar muka, sejenis dengan pengguna antar muka pada Scratch dan juga Starlogo TNG, yang memperbolehkan pengguna untuk mendrag and drop objek visual dalam mebuat aplikasi yang diterapkan pada sistem android. Dalam menciptakan App Inventor, google sudah terlebih dahulu melakukan riset yang berkaitan dengan komputasi Google telah melakukan riset yang berhubungan dengan komputasi edukasi dan pengembangan online google telah diselesaikan.

Mulyadi (2011) menjelaskan bahawa dalam lingkungan kerja aplikasi inventor terdapat komponen-komponen yang terbentuk dari komponen desainer, block editor dan juga emulator.

Location Based Service (LBS) merupakan layanan informasi yang menggunakan teknologi untuk dapat mengetahui suatu posisi. LBS memanfaatkan teknologi postioning system menggunakan teknologi sistem pemosisi yang mengizinkan pengguna untuk mendapatkan informasi lokasi yang sesuai dengan kebutuhan pengguna. LBS dibagi menjadi dua, yaitu obtain location data for a devicebased application that uses it directly dan process location data in a server and deliver result to 
device. Faktor terpenting dalam LBS adalah Location Providers (API Location) dan Location Manager (API Maps).

Data lokasi pengguna biasanya didapatkan melalui GPS (Global Positioning System) ataupun melalui jaringan telepon seluler. Komponen yang menunjang Location Based Servise dalam prosesnya yaitu, jaringan komunikasi, peranti mobile, unsur pengambilan letak longitudo (satelit) dan lattitude, data dan konten provider, dan web map server (WMS).

\section{PEMBAHASAN}

\subsection{Analisis Sistem yang dijalankan}

Sistem yang dijalankan saat ini di SMP Terang Bagi Bangsa masih menggunakan metode absensi dimana belum mengikuti perkembangan teknologi, hal ini disebabkan karena guru di SMP Terang Bagi Bangsa masih memakai absensi manual. Guru atau tenaga pengajar melakukan absensi dengan tanda tangan pada buku yang telah disediakan. Prosedur absensi sekolah dijalankan dalam beberapa tahapan seperti dalam flowmap diagram berikut :

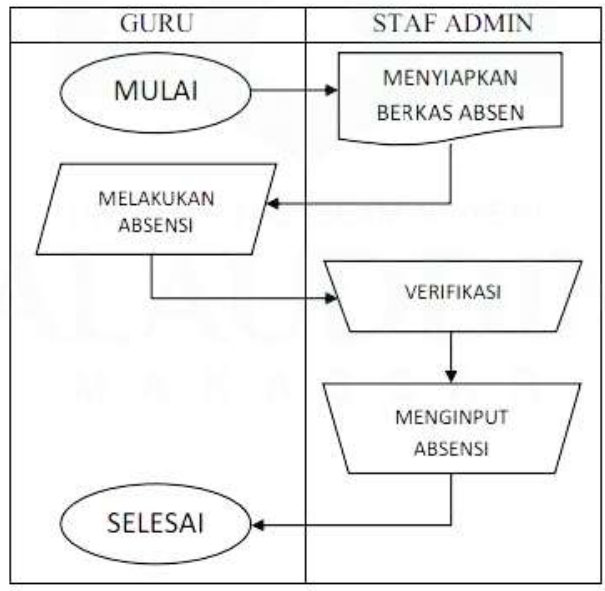

Gambar. 1 Flowmap Skema Proses Absensi Sekolah

\subsection{Analisis Sistem yang sedang dikerjakan}

Analisis sistem adalah penjabaran dari sebuah sistem utuh kedalam komponen-komponen yang digunakan untuk mengidentifikasi serta mengevaluasi suatu masalah. Analisis memiliki unsur berupa analisis kebutuhan dan analisis masalah. Dalam memciptakan suatu aplikasi dibutuhkan tahapan-tahapan dalam pengembangannya. Use case diagram, perancangan database dan aplikasi perancangan antarmuka dirancangkan berbasis android mobile.

1. Analisis Masalah

Aplikasi absensi ini akan memudahkan guru dan admin sekolah dalam mengelola data dan absensi disekolah. Aplikasi ini juga dapat memeriksa ketepatan waktu dan kehadiran pengajar.

2. Analisis Kebutuhan Sistem

a. Kebutuhan Antar muka (interface)

Perencanaan interface merupakan proses analisis guna memperoleh gambaran dari layout aplikasi yang dikembangkan. Perencanaan antarmuka (interface) dalam pembuatan aplikasi absensi ini akan penulis jabarkan dari admin dan juga android yang merupakan pengguna aplikasi.

b. Kebutuhan Data 
1) Nama tenaga pengajar dan nomer induk pegawai.

2) Tenaga Pengajar di Sekolah

3. Kebutuhan Fungsional

Kebutuhan fungsional adalah penjabaran dari proses dan fungsi secara rinci dalam setiap fungsi yang digunakan untuk penyelesaian masalah.

Fungsi-fungsi yang dimiliki, yaitu :

a. Mempermudah guru atau tenaga pengajar dalam menjalankan absensi di sekolah

b. Mempermudah admin dalam melakukan rekapitulasi data kehadiran

c. Menjalankan absensi dengan cepat dan praktis

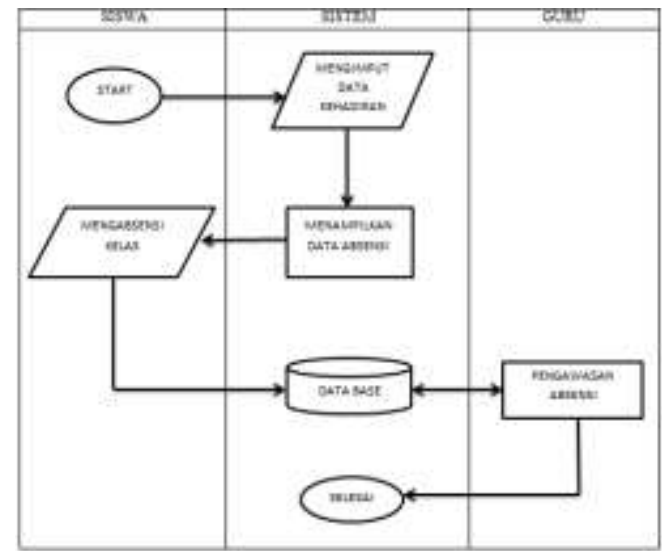

Gambar. 2 Flowmap Skema yang diusulkan

\subsection{Perancangan Sistem}

\subsubsection{Use Case Diagram}

Use Case diagram adalah gambaran skenario dari dari korelasi antara sistem dengan pengguna. Use case diagram mendeskripsikan hubungan pengguna aplikasi dengan kegiatan. Ketika melihat menu utama, penjelasan bagian-bagian yang terdapat dalam menu utama. Use case sangat mempermudah dalam memulai perencanaan suatu aplikasi karena hal tersebut merupakan hasil dari pembuatan aplikasi yang sudah dipahami. Sistem yang ada didalam aplikasi dapat digunakan oleh pengguna secara mudah karena diawal perencanaan sudah didesain sedemikian mudah. Aplikasi ini tidak banyak mempunyai button pada menu utamanya, sehingga pengguna tidak bingung saat melihat buttonnya.

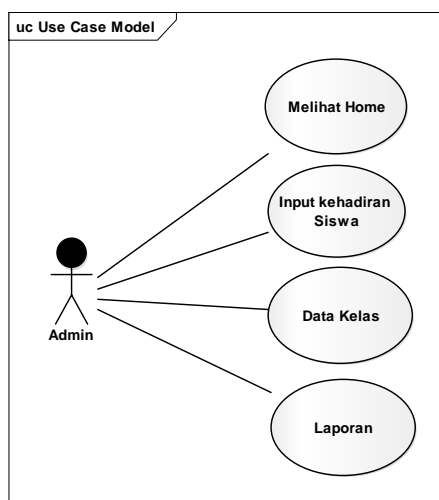

Gambar. 3 Use Case Diagram pada Admin

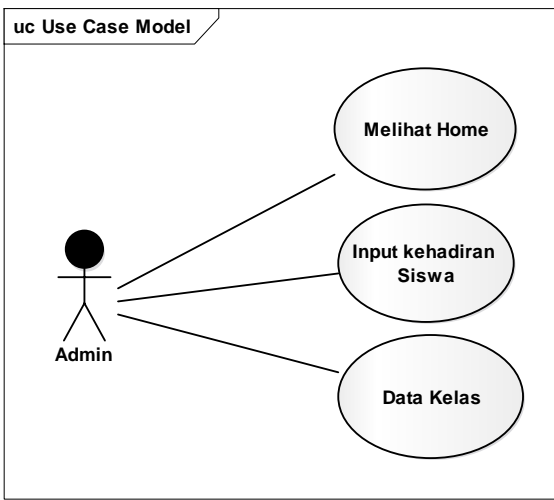

Gambar. 4 Use Case Diagram pada User 


\subsubsection{Class Diagram atau Diagram Kelas}

Class Diagram adalah diagram yang mendefinisikan struktur sistem dari kelas-kelas yang dibuat untuk mengembangkan sistem. Class Diagram memberikan rincian alur dari aplikasi yang akan dibuat.

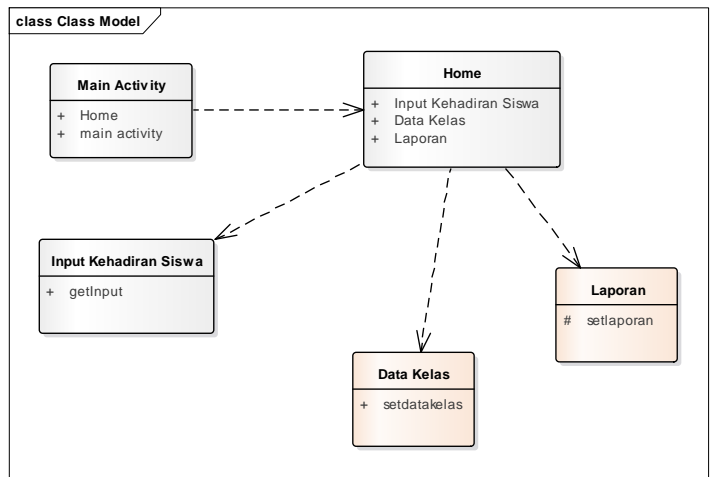

Gambar. 5 Class Diagram Admin

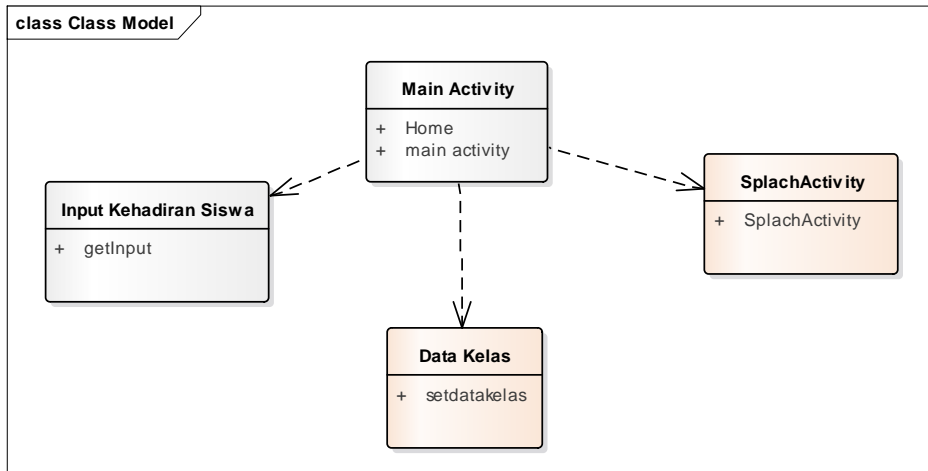

Gambar. 6 Class Diagram User

\subsubsection{Flowchart atau Bagan Alur}

Flowchart atau bagan alur merupakan chart (bagan) yang menunjukkan flow (alur) dalam suatu program secara logis. Flowchart (Bagan Alur) digunakan sebagai alat abntu komuniksi dan dokumentasi. Flowchard dari sistem adalah sebagai berikut:

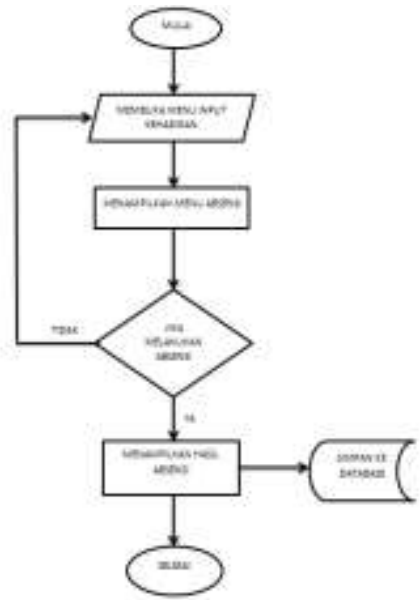

Gambar. 7 Flowchart Sistem 


\subsubsection{Perancangam Antarmuka (Interface)}

Perancangan antarmuka atau interface adalah hal terpenting dari perancangan aplikasi karena berkaitan dengan tampilan dan interaksi pengguna dengan aplikasi. Adapun perancangan antarmuka pada aplikasi ini yaitu sebagai berikut:

a. Antarmuka Menu Home

Tampilan menu home. Menu ini berfungsi menampilkan menu home aplikasi dimana kita sesudah menekan icon aplikasi absensi.

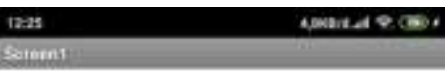

*1) Absen Online SMP Terang Bagi Bangsa

\section{Absen Kelas}

Gambar. 8 Tampilan Menu Home Aplikasi

b. Antarmuka Menu Absen Kelas

Tampilan ini adalah tampilan menu absensi sebelum melakukan absensi online.

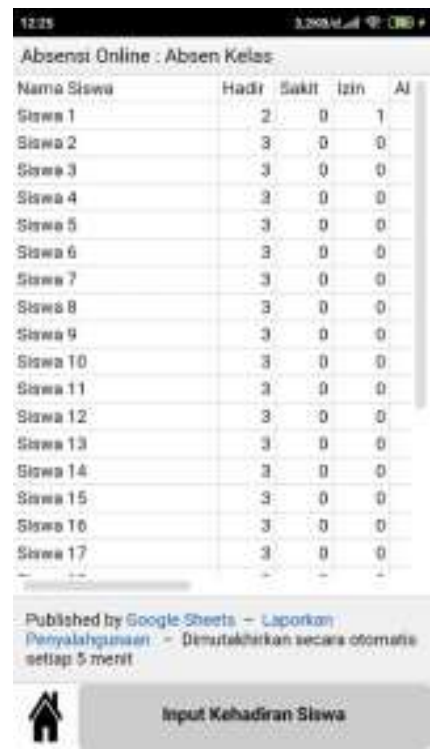

Gambar. 9 Tampilan Menu Absensi

c. Antar Muka Input kehadiran 
Tampilan ini menampilkan menu input kehadiran siswa saat melakukan absensi online, seteleh itu inputan ini akan masuk ke database sebelum ditampilkan ke data kelas.

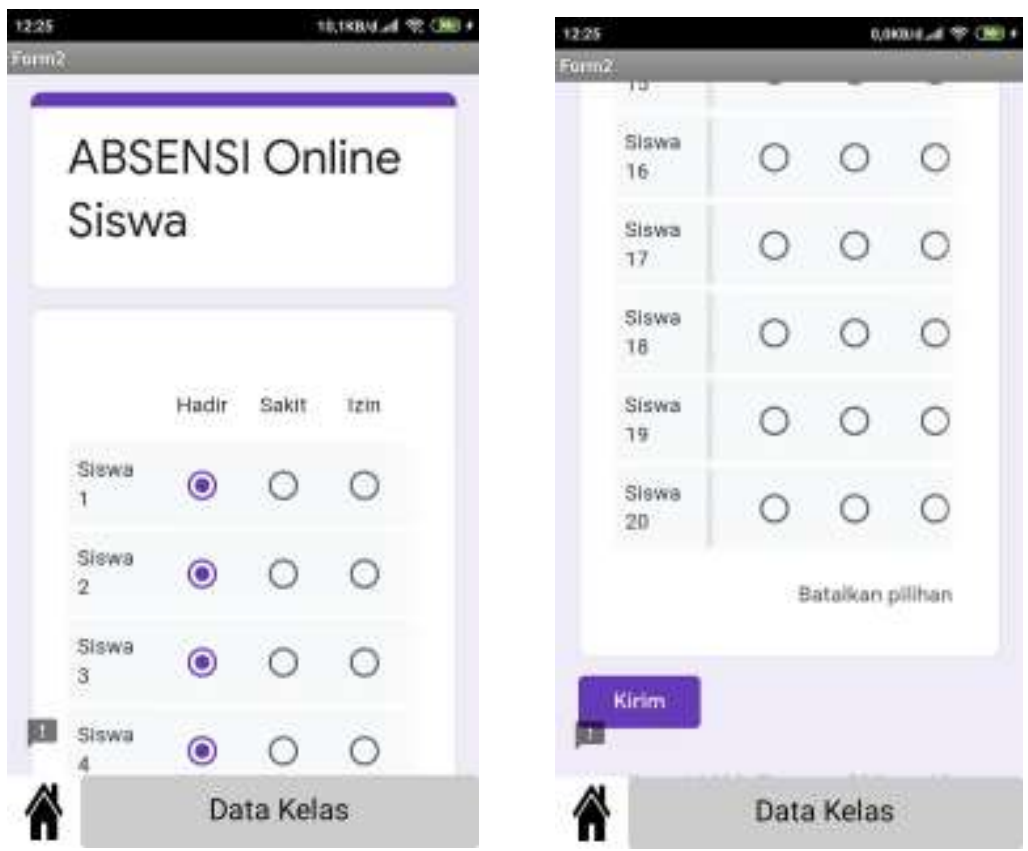

Gambar. 10 Tampilan Menu Input Kehadiran

d. Antarmuka Setelah Absensi

Ini adalah data kelas atau hasil absensi setelah melakukan input pada input kehadiran tadi dan dibawah ini terdapat hasil absensi dari hari,tanggal,ataupun bulan.

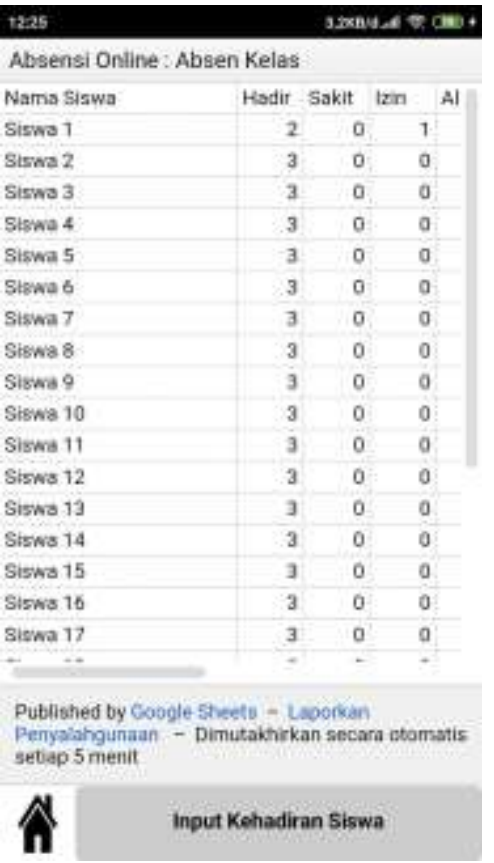

\begin{tabular}{|c|c|c|}
\hline \multicolumn{3}{|r|}{ savarea $24 \mathrm{cas}$} \\
\hline \multicolumn{3}{|c|}{ Absensi Online : Absen Kelas } \\
\hline \multicolumn{3}{|c|}{$18 / 07 / 202023-51: 2719 / 07 / 2020335519 / 07 / 2020$} \\
\hline Hadr & Hadr & $\tan$ \\
\hline Hadir & Hadr & Hadir \\
\hline Hadr & Hadir & Hadir \\
\hline Hadr & Hadr & Hade \\
\hline Hast & Hadir & Hadir \\
\hline Hadr & Hadr & Hacir \\
\hline Hasr & Hadr & Hadir \\
\hline Hadir & Hast & Hadr \\
\hline Hasir & Hadr & Hadr \\
\hline Hadr & Hadr & Hadr \\
\hline Hasir & Hadir & Hadr \\
\hline Hadir & Hadr & Hadr \\
\hline Hasir & Hadr & Hadir \\
\hline Hadir & Hadir & Hadr \\
\hline Hasir & Hadr & Hadr \\
\hline Hadir & Hadr & Hadir \\
\hline Hadr & Hadr & Hadir \\
\hline " & $\cdots 2$ & $\therefore=$ \\
\hline \multicolumn{3}{|c|}{$\begin{array}{l}\text { Pubtished by Google Sheeti - Laporkan } \\
\text { Penystahgunaan - Dimutakirkan secara otamatis } \\
\text { setap } 5 \text { menit }\end{array}$} \\
\hline & nput $k$ & Siswa \\
\hline
\end{tabular}

Gambar. 11 Tampilan Hasil Absensi

\section{KESIMPULAN}


Kesimpulan yang diperoleh dari aplikasi absensi online dapat memperbarui motede absensi yang berjalan kepada SMP Terang Bagi Bangsa. Perencanaan yang dilakukan menghasilkan sebuah sistem absensi online berbasis android dengan proses absensi dan sistem data akan diterapkan dalam smartphone android.

Aplikasi Online pada sekolah ini merupakan aplikasi inventor berbasis android dengan beberapa logika didalam sistem. Oleh sebab itu perlu dikembangkan lagi kearah yang lebih baik guna meningkatkan penggunaan aplikasi.

\section{DAFTAR PUSTAKA}

[1] Saputra, Nugraha. (2015). "Perancangan aplikasi Barcode Scanner pada sistem absensi CV. Pemindo menggunakan Android zxing library"

[2] Setyadi, Nita. (2010)“ Defenisi Sekolah” https://www.slideshare.net/nitasetyadi/definisisekolah, 2010.

[3] I Made Dharma Susila, (2013).“Sistem Absensi Mahasiswa Menggunakan Metode Qr Code Berbasis Android"

[4] Diana, (2017). "Perancangan Sistem Informasi Absensi Guru Dan Siswa Berbasis Web Di Sweet School Batam"

[5] Diyanita, Teti. (2013). "Aplikasi absensi Siswa di SMK Muhammadiyah 1 Sukaharjo Berbasis Barcode dan SMS" 